\title{
Thermodynamic analysis of synthesis of cyclopentanol from cyclopentene and comparison with experimental data
}

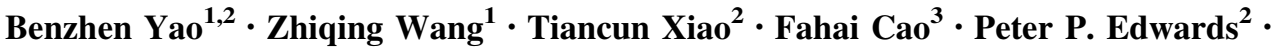 \\ Wangjing $\mathrm{Ma}^{2}$
}

Received: 4 November 2014/Accepted: 24 February 2015/Published online: 18 April 2015

(C) The Author(s) 2015. This article is published with open access at Springerlink.com

\begin{abstract}
Cyclopentanol is a very important chemical intermediate, which has been widely used in the chemical industry, and could be prepared from cyclopentene by two steps: an initial addition-esterification reaction of cyclopentene with acetic acid and the subsequent transesterification reaction with methanol. However, so far, no direct theoretical or experimental work has been reported on this process. In this work, we have carried out the thermodynamic calculation of the indirect process and also validated the thermodynamic prediction through experimental work. The liquid heat capacities of cyclopentanol and cyclopentyl acetate were estimated using the Ruzicka-Domalski group contribution method, the standard enthalpy of formation and standard entropy of gaseous cyclopentyl acetate by the Yoneda group contribution method, the standard vaporization enthalpy of cyclopentyl acetate by the Ducros group contribution method. The enthalpy changes, free energy changes, equilibrium constant and equilibrium conversion of the addition-esterification and transesterification reactions were calculated according to the principles of chemical thermodynamics in the temperature range from 273.15 to $373.15 \mathrm{~K}$. The results
\end{abstract}

Zhiqing Wang

wzq@sinopec.com

Tiancun Xiao

xiao.tiancun@chem.ox.ac.uk

1 SINOPEC Shanghai Petrochemical Company Limited, 48 Jinyi Road, Shanghai 200540, China

2 Inorganic Chemistry Laboratory, Oxford University, South Parks Road, Oxford OX1 3QR, UK

3 College of Chemical Engineering, East China University of Science and Technology, 130 Meilong Road, Shanghai 200237, China showed that both the addition-esterification reaction and transesterification reaction were exothermic, the free energy changes increased with a rise on temperature, which indicated that low temperature was favorable for the reactions in the temperature range from 273.15 to $373.15 \mathrm{~K}$. The optimal addition-esterification reaction conditions were a temperature range from 333.15 to $353.15 \mathrm{~K}$, molar ratios of acetic acid to cyclopentene in the range from $2: 1$ to $3: 1$. For the transesterification reaction, the ideal temperature ranges from 323.15 to $343.15 \mathrm{~K}$, with a molar ratio of methanol to cyclopentyl acetate in the range from $3: 1$ to $4: 1$. These thermodynamic calculation results for the addition-esterification reaction of cyclopentene and acetic acid experiments results are in good agreement with the experimental results.

Keywords Cyclopentene - Acetic acid - Methanol · Cyclopentanol - Cyclopentyl acetate - Group contribution method $\cdot$ Thermodynamic analysis

\section{Nomenclature}

List of symbols

$C_{\mathrm{p}}$ Heat capacity

$G \quad$ Gibbs energy

$H \quad$ Enthalpy

$S \quad$ Entropy

$K \quad$ Equilibrium constant

$T$ Temperature

$R \quad$ Universal gas constant

$x \quad$ Equilibrium conversion

$r \quad$ Molar ratio

$\triangle \quad$ Value of change

\section{Superscripts and subscripts}

$\theta \quad$ Standard state 
P Production

R Reactant

f Formation

r Reaction

g Gas phase

1 Liquid phase

1 Addition-esterification reaction

2 Transesterification reaction

\section{Introduction}

Cyclopentanol is an important fine chemical intermediate, which has been used in the production of perfumes, medicines and dyes, and as a solvent for medicines and perfumes [1]. The main production process for cyclopentanol was cyclopentanone hydro-conversion, and the cyclopentanone was produced by decarboxylation of adipic acid at high temperature; however, the development of this process was limited due to the formation of a great deal of pollutant $[2,3]$. Cyclopentanol can also be produced from furfural using the Noble-metal catalysts (such as $\mathrm{Pt} / \mathrm{C}$ and $\mathrm{Ru} / \mathrm{C}$ ); however, the selectivity of cyclopentanol is quite low, and future development of high efficient, stable and economical catalysts will be highly desired [4, 5].

The dicyclopentadiene could be separated from the cracked $\mathrm{C}_{5}$ fraction available as a by-product of ethylene production, and the cyclopentadiene was produced by dicyclopentadiene cracking; cyclopentene was the hydrogenation product of cyclopentadiene, and the cyclopentanol could be produced from the direct hydration or indirect hydration of cyclopentene. Theoretically, cyclopentanol could be synthesized using a two-step process from cyclopentene, e.g., the addition-esterification reaction of cyclopentene with acetic acid, the transesterification of cyclopentyl acetate and methanol, the process of hydration of cyclopentene was one environment friendly technology with less pollution [6]. The flow charts of the main production process for cyclopentanol and indirect synthesis of cyclopentanol from cyclopentene are shown in Fig. 1. However, so far, no literatures have been published for this indirect process either from the theoretical or experimental study. In this work, the thermodynamic analysis of the two reaction steps was carried out in the paper, which could provide theoretical principle for the experimental research and industrial production, and preliminary experimental work has been carried out and the results are in good agreement with the thermodynamic calculation results.

\section{Thermodynamic calculation}

\section{Reaction equations}

The two reactions have been considered in the system, the addition-esterification reaction of cyclopentene and acetic acid:

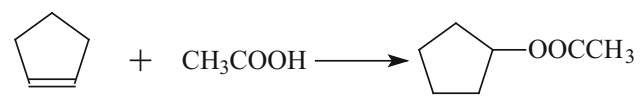

cyclopentene acetic acid cyclopentyl acetate

The transesterification of cyclopentyl acetate and methanol:

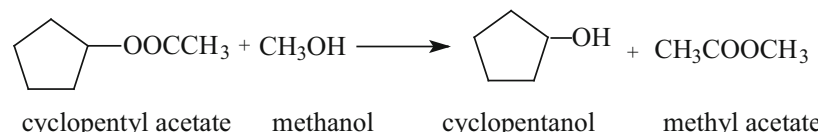

\section{Physical properties data of thermodynamic analysis}

The standard enthalpy of formation and standard entropy of liquid cyclopentene, acetic acid, methanol, methyl acetate
Fig. 1 Flow chart of the main production process for cyclopentanol and indirect sythesis of cyclopentanol from cyclopentene

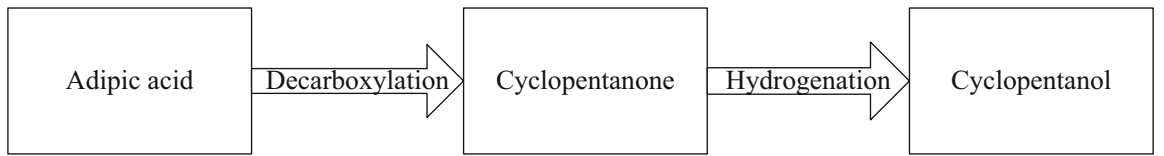

The main production process for cyclopentanol

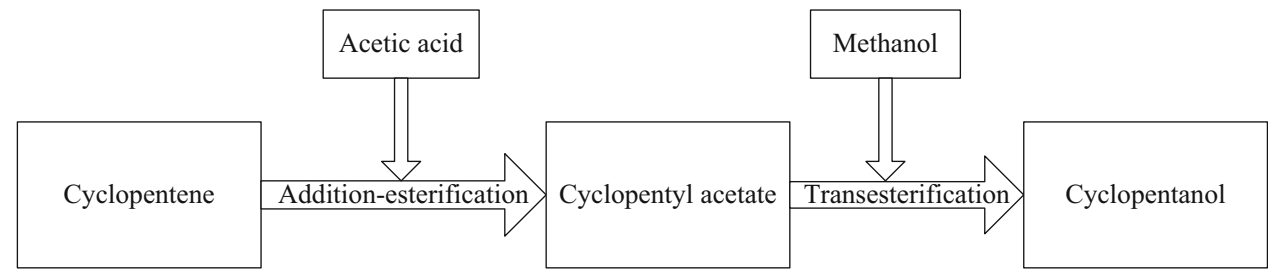

The indirect synthesis of cyclopentanol from cyclopentene 
Table 1 Contribution values of group of Ruzicka-Domalski and the group numbers in the each substance

\begin{tabular}{|c|c|c|c|c|c|}
\hline \multirow[t]{2}{*}{ Group } & \multirow[t]{2}{*}{$a_{i}$} & \multirow[t]{2}{*}{$b_{i} / \mathrm{K}^{-1}$} & \multirow[t]{2}{*}{$d_{i} / \mathrm{K}^{-2}$} & \multicolumn{2}{|l|}{ Group number } \\
\hline & & & & Cyclopentyl acetate & Cyclopentanol \\
\hline $\mathrm{C}-(\mathrm{H})_{3}(\mathrm{C})$ & 3.8452 & -0.33997 & 0.19489 & 1 & - \\
\hline $\mathrm{CO}-(\mathrm{C})(\mathrm{O})$ & 29.246 & 3.4261 & -2.8962 & 1 & - \\
\hline $\mathrm{O}-(\mathrm{C})(\mathrm{CO})$ & -21.434 & -4.0164 & 3.0531 & 1 & - \\
\hline $\mathrm{C}-(\mathrm{H})(\mathrm{C})_{2}(\mathrm{O})($ alcohol $)$ & 2.2209 & -1.435 & 0.69508 & 1 & 1 \\
\hline $\mathrm{C}-(\mathrm{H})_{2}(\mathrm{C})_{2}$ & 2.7972 & -0.05497 & 0.10679 & 4 & 4 \\
\hline Substituted cyclopentane & 0.29183 & -1.5118 & 0.23172 & 1 & 1 \\
\hline $\mathrm{O}-(\mathrm{C})(\mathrm{H})$ & 12.952 & -10.145 & 2.6261 & - & 1 \\
\hline
\end{tabular}

Table 2 The functional correlations between $C_{\mathrm{p}, \mathrm{t}}$ of materials and temperature

\begin{tabular}{ll}
\hline Constituents & $C_{\mathrm{p}, \mathrm{t}} \sim T$ \\
\hline Cyclopentene & $112.71-0.8864 T+6.2634 \times 10^{-3} T^{2}-$ \\
& $1.4632 \times 10^{-5} T^{3}+1.3021 \times 10^{-8} T^{4}$ \\
Acetic acid & $183.43-0.6817 T+2.9953 \times 10^{-3} T^{2}-$ \\
& $5.4815 \times 10^{-6} T^{3}+4.1430 \times 10^{-9} T^{4}$ \\
Methanol & $-1373.10+17.5230 T-7.9812 \times 10^{-2}$ \\
& $T^{2}+1.6112 \times 10^{-4} T^{3}-1.1979 \times 10^{-7} T^{4}$ \\
Methyl acetate & $-413.28+6.3422 T-2.7999 \times 10^{-2}$ \\
& $T^{2}+5.5006 \times 10^{-5} T^{3}-3.9106 \times 10^{-8} T^{4}$ \\
Cyclopentyl & $210.8325-0.3406 T+1.4182 \times 10^{-3} T^{2}$ \\
acetate & \\
Cyclopentanol & $221.5974-1.1293 T+3.3645 \times 10^{-3} T^{2}$ \\
\hline
\end{tabular}

and cyclopentanol were adopted from the data handbooks $[7,8]$, the results are shown in the Table 4 . The liquid heat capacities of cyclopentene, acetic acid, methanol and methyl acetate at the temperature range from 273.15 to $373.15 \mathrm{~K}$ were taken from the data handbook $[9,10]$, and the expression of liquid heat capacities was fitted as multinomial; the results are shown in Table 2 .

However, not all the physical properties of the chemicals could be obtained from handbook, the group contribution methods were investigated to estimate the physicochemical properties of organic compounds, such as Joback method [11], Constantinou-Gani method [12], Benson method [13] and so on [14, 15]. In this paper, the liquid heat capacities of cyclopentanol and cyclopentyl acetate, the standard enthalpy of formation and standard entropy of gaseous cyclopentyl acetate at the temperature of $298.15 \mathrm{~K}$, and the standard vaporization enthalpy of cyclopentyl acetate were estimated by Ruzicka-Domalski method [16], Yoneda method (ABWY) [17] and Ducros method [18, 19], respectively [20].

The liquid heat capacities of cyclopentanol and cyclopentyl acetate were estimated by Ruzicka-Domalski group contribution method $[16,20]$, the calculation formula was:
Table 3 Contribution values of group of Ducros

\begin{tabular}{llll}
\hline Constituents & Group & Number & $\begin{array}{l}\Delta H / \\
\left(\mathrm{KJ} \mathrm{mol}^{-1}\right)\end{array}$ \\
\hline Cyclopentyl & $\mathrm{C}-(\mathrm{H})_{3}(\mathrm{C})$ & 1 & 5.65 \\
acetate & $\mathrm{CO}-(\mathrm{C})(\mathrm{O})$ & 1 & 9.83 \\
& $\mathrm{O}-(\mathrm{C})(\mathrm{CO})$ & 1 & 8.37 \\
& $\mathrm{C}-(\mathrm{H})(\mathrm{C})_{2}(\mathrm{O})($ alcohol $)$ & 1 & 1.97 \\
& $\mathrm{C}-(\mathrm{H})_{2}(\mathrm{C})_{2}$ & 4 & 4.98 \\
& Cyclopentane & 1 & 2.76 \\
& adjustment & & \\
\hline
\end{tabular}

$C_{\mathrm{p}, \mathrm{t}}=R\left[A+B \frac{T}{100}+D\left(\frac{T}{100}\right)^{2}\right]$

In the Eq. $3 A=\sum n_{i} a_{i}, B=\sum n_{i} b_{i}, D=\sum n_{i} d_{i}$, the contribution values of group are shown in Table 1 and the calculation results in Table 2.The standard enthalpy of formation and standard entropy of gaseous cyclopentyl acetate at the temperature of $298.15 \mathrm{~K}$ were estimated using Yoneda method (ABWY) [17, 20], and the effect of substitutions was covered with data from Ref. [20], and the calculation formula being

$\Delta_{f} H_{\mathrm{g}, 298.15}^{\theta}=\sum n_{i} \Delta H_{i}$
$S_{\mathrm{m}, \mathrm{g}}^{\theta}=\sum n_{i} \Delta S_{i}$

The standard enthalpy of formation and standard entropy of liquid cyclopentyl acetate at the temperature of $298.15 \mathrm{~K}$ were estimated by Eqs. 6 and 7:

$\Delta_{f} H_{1,298.15}^{\theta}=\Delta_{f} H_{\mathrm{g}, 298.15}^{\theta}-\Delta_{v} H_{298.15}^{\theta}$

$S_{\mathrm{m}, 1}^{\theta}=S_{\mathrm{m}, \mathrm{g}}^{\theta}-\frac{\Delta_{v} H_{298.15}^{\theta}}{298.15}$

The standard vaporization enthalpy of cyclopentyl acetate was estimated by the Ducros method [18-20], and the contribution values of group are shown in Table 3. The 
Table 4 The $\Delta_{f} H_{l, 298.15}^{\theta}$ and $S_{m, l}^{\theta}$ of each substance at $298.15 \mathrm{~K}$

\begin{tabular}{lll}
\hline Constituents & $\Delta_{f} H_{l, 298.15}^{\theta} /\left(\mathrm{KJ} \mathrm{mol}^{-1}\right)$ & $S_{m, l}^{\theta} /\left(\mathrm{J} \mathrm{mol}^{-1} \mathrm{~K}^{-1}\right)$ \\
\hline Cyclopentene & 4.27 & 201.25 \\
Acetic acid & -484.5 & 159.8 \\
Methanol & -239.1 & 126.8 \\
Methyl acetate & -445.8 & 210.7 \\
Cyclopentyl acetate & -505.88 & 294.99 \\
Cyclopentanol & -300.1 & 206.3 \\
\hline
\end{tabular}

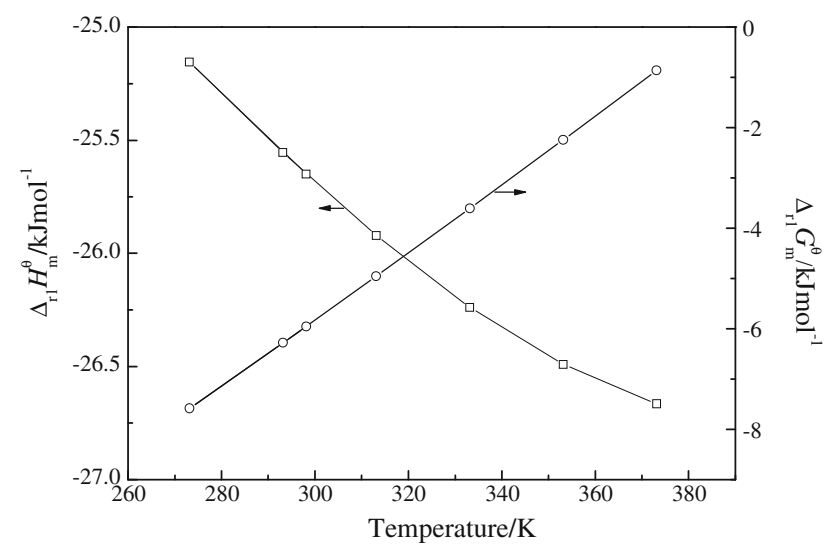

Fig. 2 The $\Delta_{r_{1}} H_{m}^{\theta}$ and $\Delta_{r_{1}} G_{m}^{\theta}$ for the addition-esterification reaction as functions of temperature

standard enthalpy of formation and standard entropy of liquid cyclopentyl acetate appear in Table 4 .

\section{Calculation results and discussion}

The enthalpy changes, free energy changes of each reaction were calculated by Eqs. 8-12 [21]:

$$
\begin{aligned}
& \Delta_{r} H_{298.15}^{\theta}=\sum\left(\Delta_{f} H_{1,298.15}^{\theta}\right)_{p}-\sum\left(\Delta_{f} H_{1,298.15}^{\theta}\right)_{R} \\
& \Delta_{r} H_{\mathrm{m}}^{\theta}=\Delta_{r} H_{298.15}^{\theta}+\int_{298.15}^{T}\left(\sum\left(C_{\mathrm{p}}\right)_{P}-\sum\left(C_{\mathrm{p}}\right)_{R}\right) \mathrm{dT}
\end{aligned}
$$

$$
\Delta_{r} S_{\mathrm{m}, 298.15}^{\theta}=\sum\left(S_{\mathrm{m}}^{\theta}\right)_{p}-\sum\left(S_{\mathrm{m}}^{\theta}\right)_{R}
$$

$\Delta_{r} S_{\mathrm{m}}^{\theta}=\Delta_{r} S_{\mathrm{m}, 298.15}^{\theta}+\int_{298.15}^{T}\left(\frac{C_{\mathrm{p}}}{T}\right) \mathrm{d} T$

$$
\Delta_{r} G_{\mathrm{m}}^{\theta}=\Delta_{r} H_{\mathrm{m}}^{\theta}-T \Delta_{r} S_{\mathrm{m}}^{\theta}
$$

The equilibrium constant of each reactions was calculated by Eq. $13[21,22]$ :

$K^{\theta}=\exp \left(-\Delta_{r} G_{m}^{\theta} / \mathrm{RT}\right)$

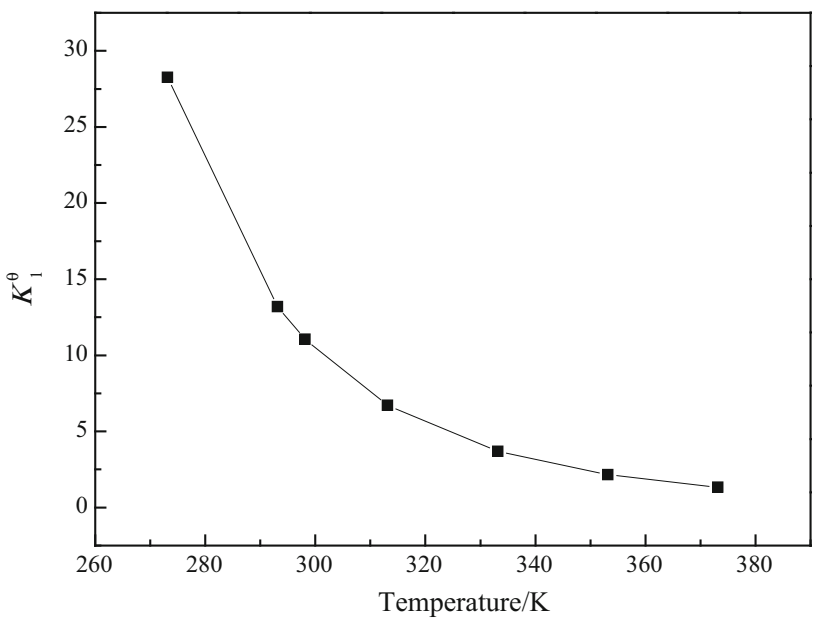

Fig. 3 Changes of the addition-esterification reaction equilibrium constant $\left(K_{1}^{\theta}\right)$ with temperature

\section{Addition-esterification reaction of cyclopentene and acetic acid}

The enthalpy changes and free energy changes of the addition-esterification reaction

The enthalpy changes $\left(\Delta_{r_{1}} H_{\mathrm{m}}^{\theta}\right)$ and free energy changes $\left(\Delta_{r_{1}} G_{\mathrm{m}}^{\theta}\right)$ of addition-esterification reaction were calculated at different temperature, the results are shown in Fig. 2.

As seen from Fig. 2, the $\Delta_{r_{1}} H_{\mathrm{m}}^{\theta}$ was less than 0 in the temperature range from 273.15 to $373.15 \mathrm{~K}$, the additionesterification reaction was exothermic, and the $\Delta_{r_{1}} H_{m}^{\theta}$ decreased with increasing temperature in the range 273.15 to $373.15 \mathrm{~K}$.

The $\Delta_{r_{1}} G_{\mathrm{m}}^{\theta}$ value was less than 0 in the 273.15 to $373.15 \mathrm{~K}$, which showed that the addition-esterification reaction could occur spontaneously. $\Delta_{r_{1}} G_{\mathrm{m}}^{\theta}$ increased with the temperature rise, which indicated that lower temperatures were more favorable for the reactions in the temperature range from 273.15 to $373.15 \mathrm{~K}$.

\section{Equilibrium constant and equilibrium conversion of the addition-esterification reaction}

The molar ratio of acetic acid to cyclopentene was set as $r_{1}$, the conversion of cyclopentene was set as $x_{1}$,so:

$K_{1}^{\theta}=\frac{x_{1}}{\left(1-x_{1}\right)\left(r_{1}-x_{1}\right)}$

The equilibrium constant $\left(K_{1}^{\theta}\right)$ of the addition-esterification reaction at different temperature was calculated from Eq. 13, and the conversion of cyclopentene as $x_{1}$ at different temperature with different $r_{1}$ was calculated from Eq. 14 and the results appear in Figs. 3 and 4. 
Fig. 4 Changes of the cyclopentene equilibrium conversion $\left(x_{1}\right)$ with temperature

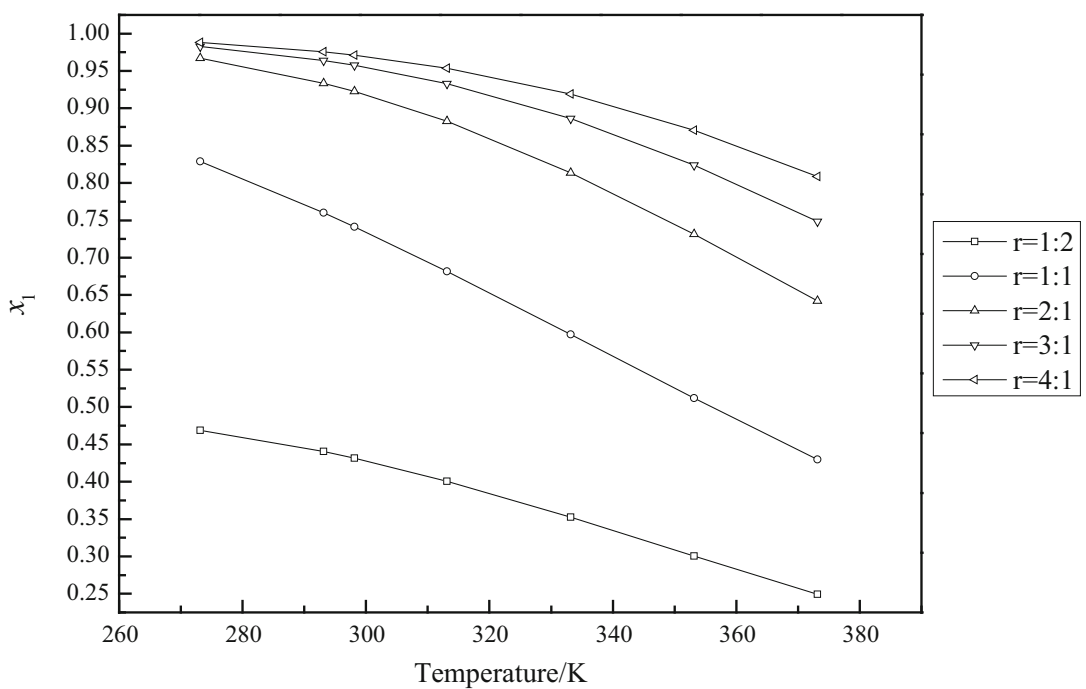

Figures 3 and 4 show that $K_{1}^{\theta}$ and $x_{1}$ decreased at higher temperature and that the $x_{1}$ increased at higher values, $r_{1}$, at the same temperature. The conversion of cyclopentene was higher at lower temperature and a greater molar ratio of acetic acid to cyclopentene. However, very low temperatures reduced the reaction rate, and the acetic acid spent increased with increasing of $r_{1}$, and the cost of separation of acetic acid and cyclopentyl acetate increased. The most suitable reaction conditions were temperature in the range from 333.15 to $353.15 \mathrm{~K}$ with an $r_{1}$ value between $2: 1$ and $3: 1$.

\section{Transesterification reaction of cyclopentyl acetate and methanol}

\section{The enthalpy changes and free energy changes of transesterification reaction}

The enthalpy changes $\left(\Delta_{r_{1}} H_{\mathrm{m}}^{\theta}\right)$ and free energy changes $\left(\Delta_{r_{1}} G_{\mathrm{m}}^{\theta}\right)$ of transesterification reaction were calculated at different temperature and the results are plotted in Fig. 5.

Figure 5 shows that $\Delta_{r_{2}} H_{\mathrm{m}}^{\theta}$ was negative in the temperature range from 273.15 to $373.15 \mathrm{~K}$, the additionesterification reaction was exothermic, and the $\Delta_{r_{2}} H_{\mathrm{m}}^{\theta}$ decreased at higher temperatures from 273.15 to $373.15 \mathrm{~K}$.

The $\Delta_{r_{2}} G_{\mathrm{m}}^{\theta}$ was greater than 0 in the temperature range from 273.15 to $373.15 \mathrm{~K}$, which showed that the additionesterification reaction couldn't carry through spontaneously. And the $\Delta_{r_{2}} G_{\mathrm{m}}^{\theta}$ increased with the raising of the temperature, which indicated that temperature increased was unfavorable for the reactions at the temperature range from 273.15 to $373.15 \mathrm{~K}$.

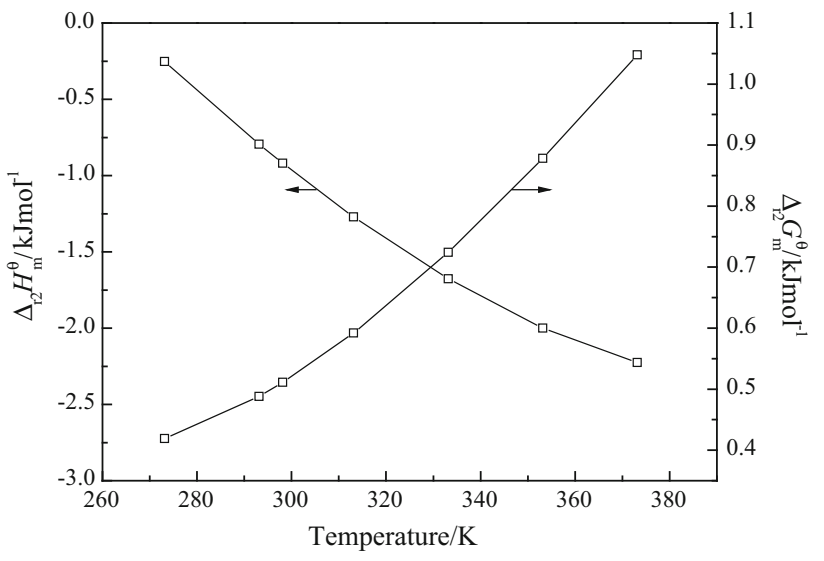

Fig. 5 The $\Delta_{r_{2}} H_{m}^{\theta}$ and $\Delta_{r_{2}} G_{m}^{\theta}$ of transesterification reaction as functions of the temperature

Equilibrium constant and equilibrium conversion of the transesterification reaction

The molar ratio of methanol to cyclopentyl acetate was set as $r_{2}$, the conversion of cyclopentyl acetate was set as $x_{2}$, so:

$K_{2}^{\theta}=\frac{x_{2}^{2}}{\left(1-x_{2}\right)\left(r_{2}-x_{2}\right)}$

In the same way, the equilibrium constant $\left(K_{2}^{\theta}\right)$ of the transesterification reaction at different temperature was calculated from Eq. 13, and the conversion of cyclopentene as $x_{1}$ at different temperature with different $r_{1}$ was calculated from Eq. 15, and the results are shown in Figs. 6 and 7.

Similarly, as seen from Figs. 6 and 7, the $K_{2}^{\theta}$ and $x_{2}$ decreased with the raising of the temperature, the $x_{2}$ increased with the raising of the $r_{2}$ at the same temperature. The conversion of cyclopentyl acetate was higher with 


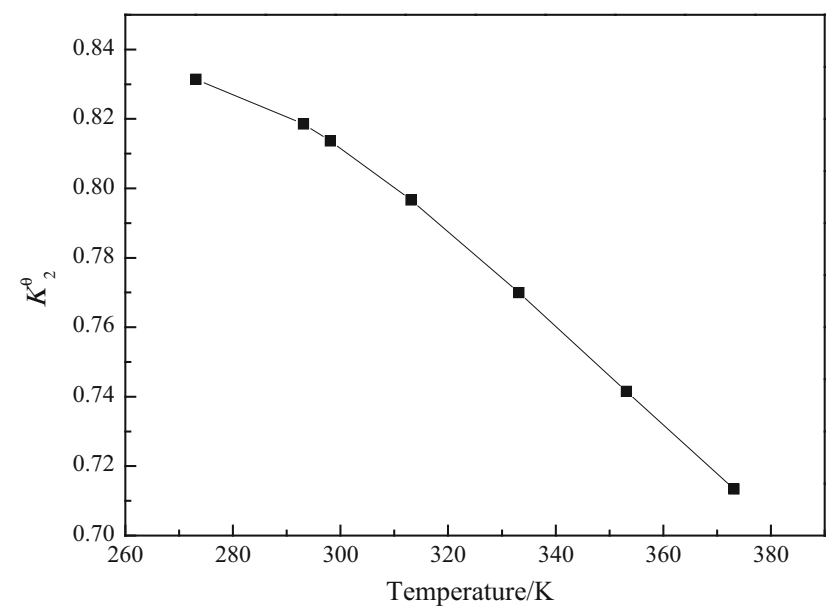

Fig. 6 Changes of the transesterification reaction equilibrium constant $\left(K_{2}^{\theta}\right)$ with temperature

lower temperature and greater molar ratio of methanol to cyclopentyl acetate. However, the extremely lower temperature reduced the reaction rate which was unfavorable for the transesterification reaction, and the methanol spent increased with increasing of $r_{2}$, and the cost of separation increased. The suitable reaction conditions were temperature of range from 323.15 to $343.15 \mathrm{~K}, r_{2}$ of range from $3: 1$ to $4: 1$.

\section{Experimental validation, results and discussion}

\section{Chemical and catalysts}

Cyclopentene [AR > $>98.0 \%(\mathrm{wt})]$ was purchased from Changzhou Sinly Pharmchem Co., Ltd. Acetic acid $[\mathrm{AR}>99.5 \%(\mathrm{wt})]$ was purchased from Reagent No. 1 Factory of Shanghai Chemical Reagent Co., Ltd. Methanol [CP $>99.9 \%(w t)]$ was purchased from Shanghai Coking Co., Ltd. Amberlyst-35 strong acidic cation-exchange resin catalysts were obtained from Rohm and Haas Shanghai Chemical Industry Co., Ltd. QRE-01 strong acidic cationexchange resin catalysts were obtained from Research Institute of Qilu Petrochemical Co., SINOPEC.

\section{Analysis and calculations}

Chemical composition of products was analyzed using a gas chromatography (Agilent GC-6890) with a HP-FFAP silica capillary column $(30 \mathrm{~m} \times 0.32 \mathrm{~mm} \times 0.25 \mu \mathrm{m})$. Nitrogen was used as the carrier gas at a flow rate of $0.7 \mathrm{~mL} / \mathrm{min}$. The temperature of column oven was programmed from $60{ }^{\circ} \mathrm{C}$ increased at $5{ }^{\circ} \mathrm{C} / \mathrm{min}$ to $80^{\circ} \mathrm{C}$, and held with an isothermal for $4 \mathrm{~min}$, then increased at $10{ }^{\circ} \mathrm{C} / \mathrm{min}$ to $220{ }^{\circ} \mathrm{C}$, and held with an isothermal for $15 \mathrm{~min}$. The temperature of injector and detector was set at 220 and $250{ }^{\circ} \mathrm{C}$, respectively. The split ratio was 1:100; the sample injection volume was $0.4 \mu \mathrm{L}$. Calibration normalization method was performed on the GC to ensure accuracy of the measurements.

The conversions of cyclopentene and cyclopentyl acetate, the selectivity of cyclopentyl acetate and cyclopentanol can be determined with the Eqs. (16-20).

$$
\begin{aligned}
& \text { Conversion of cyclopentene }(\%) \\
& =\text { Con } \\
& =\frac{m_{\text {Cyclopentene }}}{m_{\text {Cyclopentene, rawme, rawmaterials }}-m_{\text {Cyclopentene, products }}} \times 100
\end{aligned}
$$

Selectivity of cyclopentyl acetate $(\%)$

$$
=\frac{\text { Sel }_{\text {Cyclopentyl acetate }}}{m_{\text {Cyclopentene, rawmaterials }}-m_{\text {Cyclopentene, products }}} \times 100
$$

Conversion of cyclopentyl acetate $(\%)$

$$
\begin{aligned}
& =\text { Con }_{\text {cyclopentyl acetate }} \\
& =\frac{m_{\text {cyclopentylacetate,raw materials }}-m_{\text {cyclopentylacetate, products }}}{m_{\text {cyclopentyl acetate,raw materials }}} \times 100
\end{aligned}
$$

Selectivity of cyclopentanol (\%)

$$
=\operatorname{Sel}_{\text {cyclopentanol }}=\frac{m_{\text {cyclopentanol }}}{m_{\text {cyclopentyl acetate, rawmaterials }}-m_{\text {cyclopentyl acetate, products }}} \times 100
$$

Yield of cyclopentanol (\%)

$$
\begin{aligned}
& =\text { Yie }_{\text {Cyclopentene }} \\
& =\frac{\text { Con }_{\text {cyclopentyl acetate }} \times \text { Sel }_{\text {cyclopentanol }}}{100}
\end{aligned}
$$

\section{Experiment}

The addition-esterification reaction of cyclopentene with acetic acid was operated in a glass tube fixed bed reactor $(\varphi 25 \mathrm{~mm} \times 500 \mathrm{~mm})$ over Amberlyst-35 strong acidic cation-exchange resin catalysts, the reaction temperature was adjusted by the temperature control system, the reactants mass flow rate was controlled by the feeding pump. The addition-esterification reaction of cyclopentene and acetic acid with different reaction conditions was carried out under normal pressure, the mass space velocity of $2.0 \mathrm{~h}^{-1}$. The analysis results showed that the selectivity of cyclopentyl acetate was around $98 \%$. The cyclopentyl acetate product (mass fraction of $99 \%$ ) was obtained by distillation, the unreacted cyclopentene and superfluous acetic acid could be reused by distillation recovery. The conversion of cyclopentene from experimental results and the equilibrium conversion of cyclopentene from 
Fig. 7 Change of the cyclopentyl acetate equilibrium conversion $\left(x_{2}\right)$ with temperature

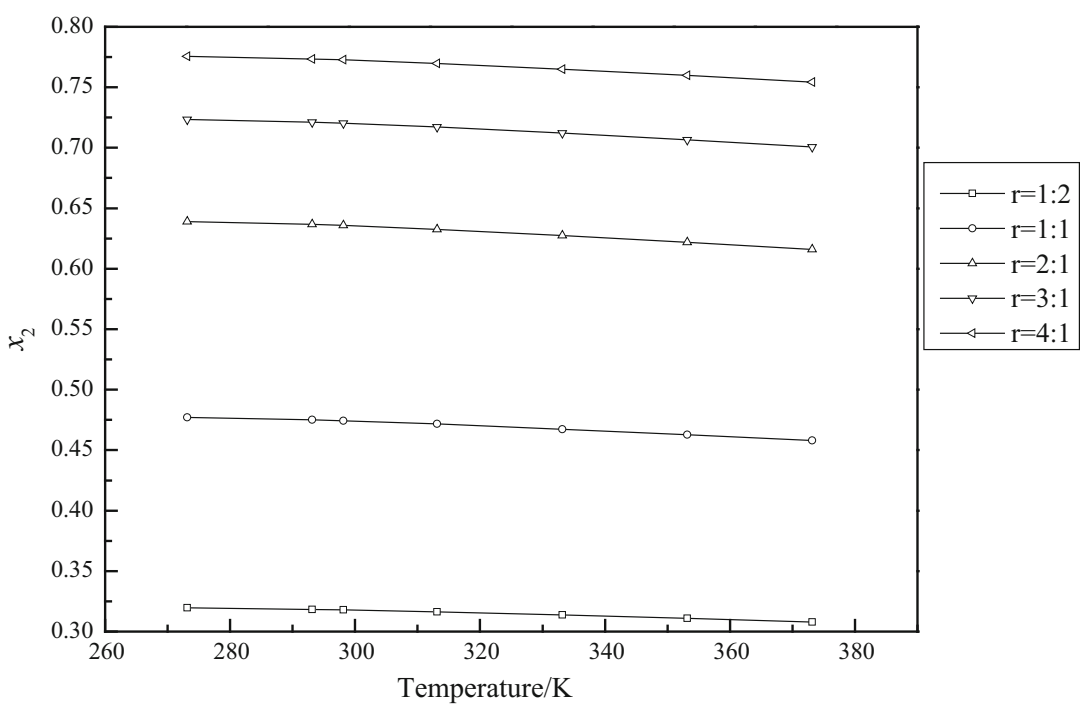

Table 5 Comparisons between experiments results and calculation data of the addition-esterification reaction

\begin{tabular}{llllllll}
\hline Experiment no. & Reaction temperature $\left({ }^{\circ} \mathrm{C}\right)$ & $r_{1}$ & \multicolumn{2}{l}{ Conversion of cyclopentene $(\%)$} & Absolute errors $(\%)$ & Relative errors $(\%)$ \\
\cline { 4 - 6 } & & & Experiments results & Calculation data & \\
\hline 1 & 65 & 1.5 & 75.43 & 71.51 & -0.0392 & -5.49 \\
2 & 65 & 2 & 77.00 & 79.41 & 0.0241 & 3.03 \\
3 & 65 & 2.5 & 81.46 & 84.13 & 0.0267 & 3.18 \\
4 & 65 & 3 & 84.38 & 87.19 & 0.0281 & 3.22 \\
5 & 65 & 3.5 & 85.63 & 89.29 & 0.0366 & 4.10 \\
6 & 50 & 3 & 75.94 & 91.14 & 0.1520 & 16.68 \\
7 & 55 & 3 & 79.82 & 89.93 & 0.1011 & 11.24 \\
8 & 60 & 3 & 82.81 & 88.61 & 0.0580 & 6.54 \\
9 & 65 & 3 & 84.38 & 87.19 & 0.0281 & 3.22 \\
\hline
\end{tabular}

$r_{1}$ molar ratio of acetic acid to cyclopentene

thermodynamics calculation in the addition-esterification reaction are compared in Table 5.

From Table 5, we can see that, the cyclopentene conversion relative errors of experiment nos. 6 and 7 were more than $10 \%$. Since the reaction rate I was slower in the lower temperature, it was difficult to achieve equilibrium at a lower reaction temperature during a short reaction time, the relative errors in the lower reaction temperature were larger than that in higher reaction temperature. The relative error of other experiments was lower than $7.0 \%$, and the average relative error was $2.98 \%$ (experiment nos. 6 and 7 are not included); the thermodynamic calculation was in good agreement with the experiment results.

The transesterification of cyclopentyl acetate and methanol was operated in a glass tube fixed bed reactor $(\varphi 25 \mathrm{~mm} \times 500 \mathrm{~mm})$ over QRE-01 strong acidic cationexchange resin catalysts, the reaction temperature was adjusted by the temperature control system, the reactants' mass flow rate was controlled by the feeding pump. The transesterification of cyclopentyl acetate and methanol was carried out under normal pressure, the reaction temperature of $50{ }^{\circ} \mathrm{C}$, the molar ratio of methanol to cyclopentyl acetate of $3: 1$, the mass space velocity of $2.0 \mathrm{~h}^{-1}$, the conversion of cyclopentyl acetate was $55.3 \%$, the selectivity of cyclopentanol was $99.5 \%$, the yield of cyclopentanol was $55.0 \%$. The cyclopentanol product was obtained by distillation, the unreacted cyclopentyl acetate and superfluous methanol could be reused by distillation recovery.

\section{Conclusions}

Thermodynamic analysis for reactions of indirect synthesis of cyclopentanol from cyclopentene has been carried out based on partial physical properties data of cyclopentyl acetate and cyclopentanol estimated by group contribution 
methods. The enthalpy changes, free energy changes, equilibrium constant and equilibrium conversion of the addition-esterification reaction and transesterification reaction were calculated.

The addition-esterification reaction of cyclopentene and acetic acid was exothermic reaction at the temperature range from 273.15 to $373.15 \mathrm{~K}$, the optimal reaction condition was temperature of range from 333.15 to $353.15 \mathrm{~K}$, molar ratio of acetic acid to cyclopentene of $2: 1-3: 1$.

The transesterification reaction of cyclopentyl acetate and methanol is exothermic reaction at the temperature range from 273.15 to $373.15 \mathrm{~K}$, the optimal reaction condition was temperature of range from 323.15 to $343.15 \mathrm{~K}$, molar ratio of methanol to cyclopentyl acetate of $3: 1$ to $4: 1$.

The addition-esterification of cyclopentene and acetic acid experiments were carried out in a glass tube fixed bed reactor, and the experiments results showed that the thermodynamic calculation was in good agreement with the experiment results.

Open Access This article is distributed under the terms of the Creative Commons Attribution License which permits any use, distribution, and reproduction in any medium, provided the original author(s) and the source are credited.

\section{References}

1. Ordomsky VV, Schouten JC, Van der Schaaf J et al (2013) Biphasic single-reactor process for dehydration of xylose and hydrogenation of produced furfural. Appl Catal A 451:6-13

2. Guo ShZh, Huang YR, Xu ZH, Huang HS, Fang L, Fang DY (2004) Preparation of cyclopantanol by hydration of cyclopentene. J East China Univ Sci Technol 30(6):618

3. Meng XY, Chen XR, Chen XY (2011) Study on catalytic hydration of cyclopentene to cyclopantanol. J Hebei Univ Technol 40(2):46

4. Yan K, Wu G, Lafleur T et al (2014) Production, properties and catalytic hydrogenation of furfural to fuel additives and valueadded chemicals. Renew Sustain Energy Rev 38:663-676

5. Yan K, Liao J, Wu X et al (2013) A noble-metal free Cu-catalyst derived from hydrotalcite for highly efficient hydrogenation of biomass-derived furfural and levulinic acid. RSC Adv 3(12):3853-3856

6. Xu ZH, Chang H, Xia RH, Ye JM, Zh YJ (2012) CN $102399132 \mathrm{~A}$
7. Dean JA (1999) Lange's handbook of chemistry, 15th edn. McGraw-Hill Book Co, New York

8. Li ML (2003) Concise handbook of chemical data. Chem Ind Press, Beijing

9. Liu GQ, Ma LX, Liu J (2002) Chemistry and chemical engineering physical properties databook. Chem Ind Press, Beijing

10. Fu B (1997) Common chemistry handbook. Geological Press, Beijing

11. Joback KG, Reid RC (1987) Estimation of pure-component properties from group-contributions. Chem Eng Commun 57(1-6):233-243

12. Constantinou L, Gani R (1994) New group contribution method for estimating properties of pure compounds. AICHE J 40(10): $1697-1710$

13. Benson SW, Cruickshank FR, Golden DM et al (1969) Additivity rules for the estimation of thermochemical properties. Chem Rev 69(3):279-324

14. Kolská Z, Ruzická V, Gani R (2005) Estimation of the enthalpy of vaporization and the entropy of vaporization for pure organic compounds at $298.15 \mathrm{~K}$ and at normal boiling temperature by a group contribution method. Ind Eng Chem Res 44(22): 8436-8454

15. Kolská Z, Kukal J, Zábranský M et al (2008) Estimation of the heat capacity of organic liquids as a function of temperature by a three-level group contribution method[J]. Ind Eng Chem Res 47(6):2075-2085

16. Růžička V Jr, Domalski ES (1993) Estimation of the heat capacities of organic liquids as a function of temperature using group additivity. II. Compounds of carbon, hydrogen, halogens, nitrogen, oxygen, and sulfur. J Phys Chem Ref Data 22(3):619-657

17. Yoneda Y (1979) An estimation of the thermodynamic properties of organic compounds in the ideal gas state. I. Acyclic compounds and cyclic compounds with a ring of cyclopentane, cyclohexane, benzene, or naphthalene. Bull Chem Soc Jpn 52(5):1297-1314

18. Ducros M, Gruson JF, Sannier H (1980) Estimation of the enthalpy of vaporization of organic compounds in the liquid phase. Part 1. Alkanes, cycloalkanes, alkenes, aromatic hydrocarbons, alcohols, thiols, chloro-and bromoalkenes, nitriles, esters, acids and aldehydes. Thermochim Acta 36:39-65

19. Ducros M, Gruson JF, Sannier H et al (1981) Estimation des enthalpies de vaporisation des composes organiques liquides. Partie 2. Applications aux ethersoxydes, thioalcanes, cetones et amines[J]. Thermochim Acta 44(2):131-140

20. Ma PSh (2003) Chemical engineering data, 1st edn. China petrochemical Press, Beijing

21. Hu Y, Lv RD, Liu GJ, Ye RW (1999) Physical chemistry, 4th edn. Higher Education Press, Beijing

22. Cao FH, Liu DH, Hou QSh, Fang DY (2001) Thermodynamic analysis of $\mathrm{CO}_{2}$ direct hydrogenation reactions. J Nat Gas Chem 10(1):24 